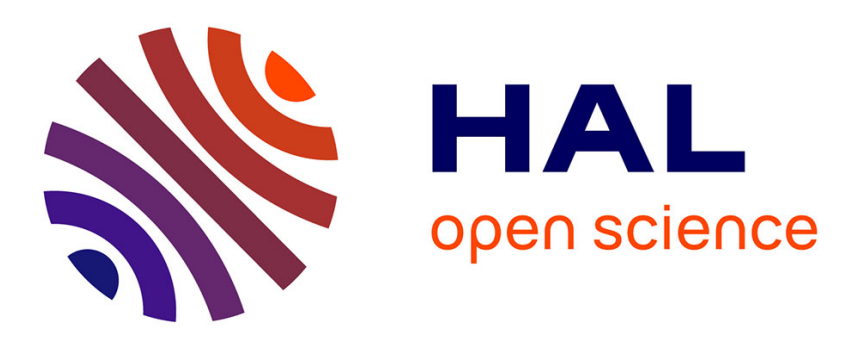

\title{
Materiality, Maintenance and Fragility. The Care of Things
}

Jérôme Denis, David Pontille

\section{To cite this version:}

Jérôme Denis, David Pontille. Materiality, Maintenance and Fragility. The Care of Things. 'How Matter Matters', Third International Symposium on Process Organization Studies, Jun 2011, Corfu, Greece. halshs-00602914

\section{HAL Id: halshs-00602914 https://shs.hal.science/halshs-00602914}

Submitted on 23 Jun 2011

HAL is a multi-disciplinary open access archive for the deposit and dissemination of scientific research documents, whether they are published or not. The documents may come from teaching and research institutions in France or abroad, or from public or private research centers.
L'archive ouverte pluridisciplinaire HAL, est destinée au dépôt et à la diffusion de documents scientifiques de niveau recherche, publiés ou non, émanant des établissements d'enseignement et de recherche français ou étrangers, des laboratoires publics ou privés. 


\title{
Materiality, Maintenance and Fragility The Care of Things
}

\author{
Jérôme Denis \\ Telecom ParisTech \\ 46, rue Barrault 75013 Paris - France \\ denis@telecom-paristech.fr \\ David Pontille \\ CNRS/EHESS \\ 105, bd Raspail 75006 Paris - France \\ pontille@ehess.fr
}

\section{'How Matter Matters', Third International Symposium on Process Organization \\ Studies, Corfu, June 16 $6^{\text {th }}-19^{\text {th }} 2011$.}

\begin{abstract}
This communication attempts to go beyond a definition of materiality, largely accepted in organization studies, that only focusses on consistency and stability. Drawing on the results of an ethnography of subway signs maintenance it highlights the importance to consider material fragility and vulnerability, particularly in the case of ordering devices. Following maintenance workers helps to understand that the stability of artifacts is not an ontological property but the ongoing result of an exploratory and improvised work that consists in constantly taking care of things and being aware of their material multiplicity.
\end{abstract}

\section{Keywords}

Matter - Fragility - Maintenance - Ordering devices - Artifacts - Care - Subway Signs 
'When transported to other sites and situations, the logic of care articulated here will have to be translated'. (Mol 2006: 91)

Materiality and its role in organization processes are an important but somehow hazy issue. As Orlikowski and Barley (2001) notably point out, the main problem about the majority of theories that highlight material properties of technical systems is twofold: they draw on an abstract definition of both materiality and technology, without dealing with concrete artifacts; and they tend to reduce materialism to determinism. Furthermore, these perspectives (contengency theory or media richness theory for instance) tend to draw clear distinctions between 'material' and 'social' properties, which are not satisfying (Leonardi and Barley 2008). These reproaches made in organization studies are more or less similar to the those addressed by Ingold to material culture studies, where the use of the notion of materiality is generally too encompassing, and where 'the polarity of mind and matters remains' (Ingold 2007, p. 3).

Beyond accusations of determinism, materiality raise another issue in organization studies. It seems, indeed, that ever in the more cautious studies tackling the question, materiality is almost exclusively discussed in terms of consistency, or at least tangibility (Leonardi 2010). Paradigmatic of such a posture is the use of such notions as 'objectification' and 'reifification'. Material properties of artifacts are most of the time described as components that bring some resistance: whether they give to artifacts the ability to constraint users' action or, on the contrary, wether they provide practical resources. Such a 'materiality-as-stability' approach is particularly present in management studies, where post-giddensian researches emphasize materiality as a key feature of structuring processes. Artifacts and technologies are studied here mainly as inanimate objects within which social relations or political categories are gradually frozen. One can find more or less the same vocabulary in what J. Law termed a 'managerialist' appropriation of Actor-Network Theory (Law 1999: 5) which studies artifacts agentivity with a narrow and non-relational definition of such notions as 'black boxes' or 'immutable mobiles'. In this perspective, successful and viable objects are essentially seen as the material result of the stabilization of a sociotechnical network.

The problem with such approaches lies in the fact that materiality is somehow taken for granted, at least by actors, and often by researchers themselves. Artifacts and technologies are described as distinct and solid objects, and their frontiers or robustness are rarely questioned (Pels et al 2002). This is not only the case in 'perspectivism' and 'representationalism', for which materiality goes hand in hand with univocity, and plurality comes only from actors' interpretations (Mol 1999; Barad 2003), but also in the 'naive formalism' (Star 1995; Berg 1997) adopted by the numerous researches that treat material properties of information technologies as intrinsic structuring components.

Recently, W. Orlikowski (2007) made a plea for a new consideration of materiality in organization. Even if it was mainly turned against the lack of discussion about materiality in organization studies, her position can also be seen as a response to the approaches discussed above. Orlikowski and her colleagues indeed refuse to specify material aspects of technologies and to isolate their action. Instead, they defend a situated and practice-based point of view (Suchman 1987; Gherardi 2001), from which what counts is 'technology-in-use' rather than technology itself (Orlikowski 2000). Here then, matter matters in terms of process and hybridity and the 'entwining of the material and the social' (Leonardi and Barley 2008) is the main issue that have to be explored.

In a communicational perspective, a similar move has been made by researchers who have emphasized the role of texts within organizations, not simply as powerful material vehicles for information, but as full agent. This is notably what F. Cooren and his colleagues have done, 
urging organization (and communication) scholars to take into account the plurality of such an agentivity. Cooren notably shows that ambiguity and undecidability are the roots of texts' agency within organizations (Cooren 2010): it is precisely because the meaning and the force of documents and technologies are unpredictable that they do really count. Such a consideration focuses on the place of texts and their materiality within the constant dialogues that punctuate organizing processes.

These streams of research defend an ecological view of materiality within organizations. They certainly point out the importance of objects and artifacts in the dynamics of ordering and structuring, but they refuse to impute stability to material properties only: what is at stake here is the 'inherent sociomaterial nature of organizational practices' (Orlikowski 2007).

This displacement is essentially due to an interest in agency as an essential theoretical issue (more than social structures or organizations). The numerous studies conducted within this framework highlight the active role of hybrid assemblages within which humans and nonhumans are closely connected (Barad 2003; Latour 2007). To question agency in these terms prompts scholars to ignore the vocabulary of materiality-as-stability (or tangibility), and to develop instead a more dynamic and processual approach. As Leonardi recently wrote, some researchers even voluntarily use 'materiality' and 'material' in a very broad sense, which simply refers to performativity as a sociomaterial process (Leonardi 2010).

In this communication, we propose to complement such a program in pointing another way to question the place of materiality in organizational processes and to challenge the stability and tangibility version. For that, we will step aside from the traditional organization studies: instead of investigating the way people work, and act, with artifacts and objects, we will take a close look at the way some people directly work on things. This is especially the case of repair and maintenance practices, which have been largely overlooked in organization studies. Because they deal with the very vulnerability of things, focusing on these practices gives the opportunity to explore a very different side of the material features of artifacts. A side where materiality can definitively not been considered as a synonym of consistency.

Drawing on the results of an ethnography of Parisian subway signs repair and maintenance (Denis and Pontille 2010a), we address three main issues. First, we show that subway signs can be analyzed, in the materiality-as-stability framework, as ordering devices (1). Second, through the exploration of maintenance workers practices, we focus on heterogeneity (2) and fragility (3) as important material features of signboards, however normalized they are. Third, we go back to the question of sociomaterial agency in order to highlight the particular contribution of repair and maintenance studies. Because maintenance practices imply a specific engagement with matter, which emphasizes vulnerability, we draw a parallel between maintenance and what A. Mol (2008) terms the 'logic of care' in medical practices, assuming that 'the care of things' could be a promising domain of research.

\section{Ordering}

Wayfinding systems are essential devices amongst the numerous immobile infrastructures that support and organize mobility (Amin and Thrift 2002, Urry 2007, Knox et al. 2008). They provide a graphical layer dedicated to the accountability of places and the everyday organization of public settings. Street nameplates, traffic lights or signboards inform passersby about their own location in the city ('this' neighborhood, 'this' street) and give indications about the suitable behavior they have to adopt ('stop here', 'turn left'). By marking sites, giving places a name, designating directions, these signs are what Garfinkel (1996) terms 'territorial organizational things'.

In the case of Paris, subway signs became a central issue for the Régie Autonome des Transports Parisiens (RATP) at the beginning of the 1990s. At this time, a team of specialists 
(designers, cartographers and architects) was brought together with the aim of reconsidering the whole organization of subway signs. Surveys, field studies and experiments were conducted. This resulted in the creation of a complete wayfinding system and the writing of a particularly ambitious policy.

This policy was organized around two main principles. The first one is multimodality. Before the 1990's, each transportation mode had its own particular wayfinding system with its own typography and colors. The new wayfinding system has been conceived as a means to transcend these differences. The same set of signs has been designed and implemented for each transportation mode provided by the carrier: subway, regional trains, bus, tramway, and so forth. The main goal was to offer a seamless service to riders: from then on, they could circulate through the whole city by following the same kind of signs from one transportation mode to another.

The second principle is omnipresence. Numerous new boards have been created and signage occupies now every possible positions in the transportation network. This is a very specificity of the Parisian subway system compared to other wayfinding systems in the world. In Paris, each junction, corridor, hall, stairs, and plate-form has been fully equipped with a board. Such a policy contributes to the production of an hybrid environment which is no more an architectural space only and where the distinction between the building and its signs, between the text and the territory, becomes indistinct' (Fuller 2002: 236).

These two principles, multimodality and omnipresence, were supported by the writing of an ambitious standardization policy, which was a big first in the history of Parisian subway signs. The previous wayfinding systems used to stand in few documents and used to be transmitted or recalled on the basis of an oral tradition: since someone needed to change a board or to get a new one, someone else would explain it to her with more or less precisions. Conversely, new signboards have come out with extremely precise guidelines, detailed in voluminous files. Every dimensions of signboards are now strictly standardized: content, shape, size, colors and emplacement. Standardization then turned the whole wayfinding system into a powerful means of homogenization and stabilization of subway spaces.

Regardless the location, signage is endless repeated and declined, always perfectly the same, according to the established rules. Repetition creates unity, promotes the recognition, and enhance the comfort of the riders. (Internal document, RATP 1997: 5)

Such a normalization policy has had consequences beyond the signboards themselves. For instance, the uses of names themselves have been homogenized in a document entitled 'official denomination' that specifies the rules to follow in order to identically designate places through the variety of settings and media. Subway signs standardization has thus lead to the public display of a stabilized version of names that remained more or less changing until then. Sometimes an unofficially denomination has even been created.

The name used to indicate a place has to be as short as possible, and close to everyday language. Therefore, official designation will not be systematically taken up. (For instance: 'Centre Georges Pompidou' instead of 'Centre National d'Art et de Culture Georges Pompidou'). (Guide Information Voyageurs, RATP 2007: 22)

Focusing on the standardization process clearly prompts to analyze subway signs in terms of material consistency and stability. Actually, emplacement, shape, size and content normalization fits perfectly with the vocabulary of immutability as emphasized by the first version of Actor-Network Theory (Law 1999). Because of their immutability and their recurrence, subway signs perform a graphical environment that not only smooths out the architectural differences but also shapes several easily identifiable zones in each stations: halls, corridors, platforms... 
From this standpoint, subway signs are powerful ordering devices: a set of immutable artifacts whose standardization and material consistency mold a stabilized infrastructure dedicated to mobility. Such an assertion is perfectly acceptable and gives an accurate account of the Parisian signage policy. An account that insists on the role of material consistency in ordering processes, and draws a centralized and strategic version of Parisian subway signs, a foucaldian one, some would say.

Assuming such an account amounts to perform a specific reality (Law and Singleton 2000), where consistency and materiality are two synonymous dimensions of agency. But what do we miss with it? Which parts of the reality of subway signs slip away from us when we describe such an orderly phenomena? A lot, obviously. But, mainly, what this version of subway signs does not give any chance to is mess (Law 2004). And yet, even if it is better known in workplace studies than in organization studies, mess is a very common aspect of organizations. Moreover, mess is a very material phenomena: just think of all you have to handle, to move or to throw away when you decide to tidy up your office. Dirt also is material: you will probably wash your hands after that.

So, how can we appreciate the messy version of subway signs, and more generally, the messy materiality of organizational processes? Following the precursory works of Orr (1996), Henke (2000) and Graham and Thrift (2007), we think that studying cleaning or repairing practices can be extremely useful for that purpose. Indeed, to understand the mess, we should ask with S.L. Star : 'Who is doing the dishes? Where does the garbage go?' (Star 1995 , p. 3). This is a way to question the 'material basis for practices' (p. 3), not focusing on the 'noble' side of matter. It is also a way to consider the role of people who take care of the garbage and repair stuffs in the ongoing production of social order.

In Parisian subway system, these people are numerous. However, few workers are fully dedicated to subway signs: they are gathered in the signage maintenance department. In this communication, we focus on the work of the four maintenance operators who were in charge of signs installation, repair and replacement at the time of our ethnography. We already pointed out the richness of their practices, which implies specific competencies (Denis and Pontille 2010a, 2010b). We only investigate here their engagement with signboards material properties, which allows us to highlight two main aspects of signs: their material heterogeneity and their fragility.

\section{Heterogeneity}

We saw that, in the designers discourse and in the guidelines, the signs that compose the Parisian wayfinding system are clearly identified as stabilized material objects whose size, shape, and materials have been normalized. But in the day-to-day maintenance practices, things are not that clear: when it comes to repair them or even put them up, signboards do not appear so consistent.

Above all, for maintenance workers, subway signs are never completely closed and finite objects. During their work, they change and go through distinct states. In the course of an intervention, a sign can for instance switch in few minutes from an electric board to a pile of screws next to a plastic sheet and a transparent display. What was present in the situation as a simple artifact suddenly turns into a list of various materials.

Nathan and Stephan have to change a board in order to update its information. The amount of handling they have to do for this seemingly simple operation is surprising. Sixteen small screws have to be removed from the metal frame in order to take down the broken board (fig. 1). Once it is done, they put up the new plaque very carefully: a false move could damage it. Then they screw back the frame before hanging it up on the ceiling. 


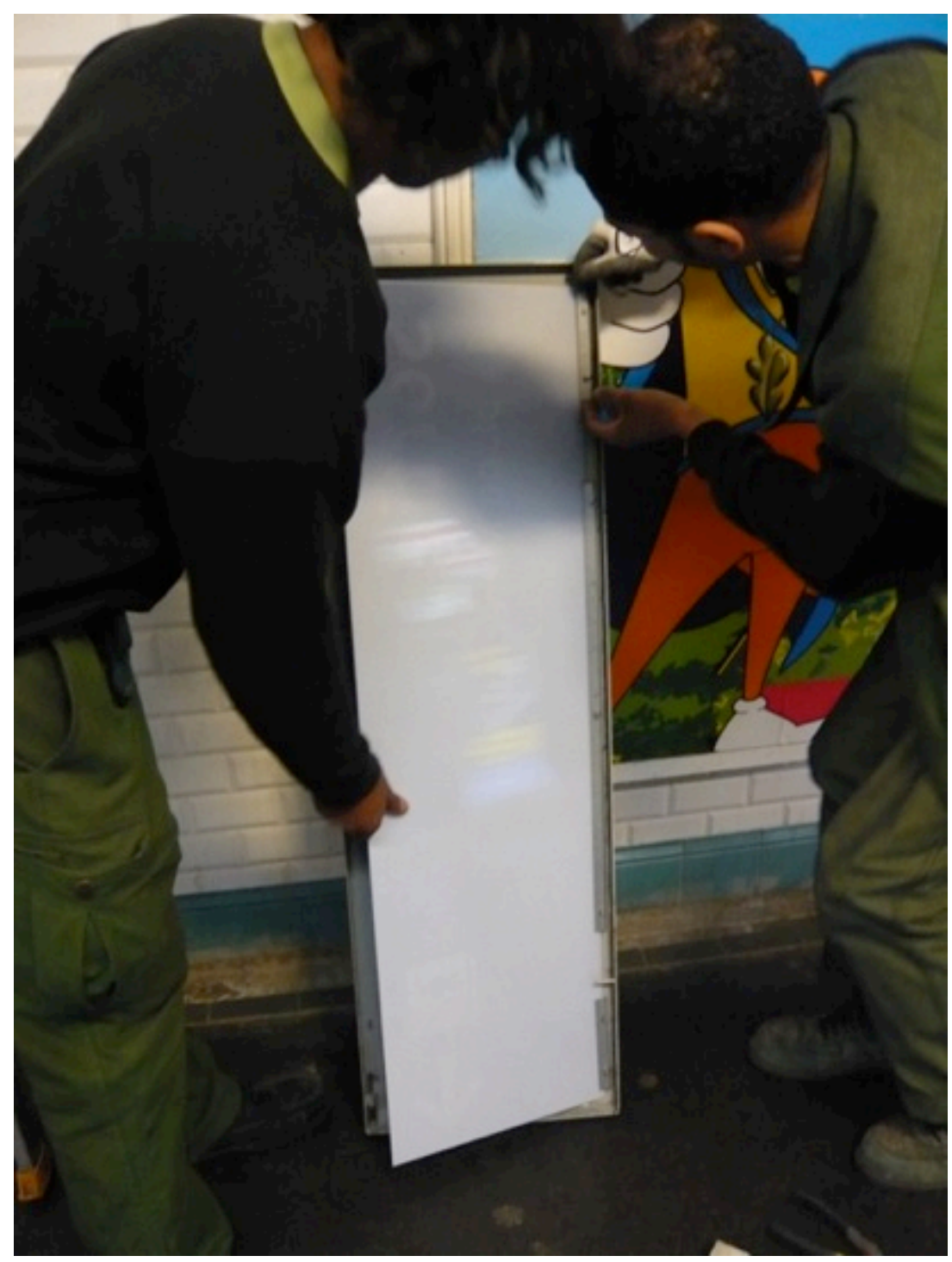

Figure 1. Disassembling a signboard

A large part of the daily activity of the maintenance operators consists in dismantling or jointing various signage components. In their hands, signboards are not the single objects sought by designers: they appear as heterogeneous assemblages whose form evolves according to the steps of their work. What is important here is the transitivity of the process. Disassembling is of course essential in repair and maintenance practices, but not more than assembling. As repaired and maintained objects, signboards can change from a mode of existence to another in both directions: from a unified entity to scattered heterogeneous parts, and back to a consolidated artifact. These changes never occur at the same time, they are essential steps in what we could term, imitating Pickering (1995), the 'dance of maintenance'.

There is another part of maintenance practices that highlights the material heterogeneity workers deal with. Repairing or installing a signage component does rarely imply a sole signboard, even if the latter keeps its original form. In almost every situations, maintenance workers have to take other things into consideration, and particularly the material layers that interpose between the enameled board and the concrete of the wall. To put up a new board or to repair an old one, they have to deal at least with tiles, plaster, glue, screws and metal brackets. Thus, during their interventions, what appear for the mundane observer as a seamless association of two distinct objects (the board and the wall) is both unfurl and 
blurred. Maintenance workers go through what one would see as the 'natural' boundaries of things, and explore and test the relations of components that can not be assigned to a specific 'object'.

These insights show that a very particular version of subway signs occurs during maintenance work. Here, signboards are not handle as stabilized objects and their material properties are not 'those tangible resources that provide people with the ability to do old things in new ways and to do things they could not do before' (Leonardi and Barley 2008: 161). Moreover, this is not the 'materiality' of signs that counts for maintenance operators (since it literally spreads out in heterogeneous components), but the diverse materials that are no more, or not yet, crystallized in clearly distinguishable objects (Ingold 2007).

Two things are important here. First, the mess itself. It is clear that during maintenance work, signboards, bindings and walls materials, in their very diversity, can not be seen as agents of an ordering process. They do not provide a solid support for the workers action either. On the contrary, they generally are objects of worries: will the glue hold? Should the concrete be covered? Will we be able to remove these screws? How much dry is the plaster? This particular version of signboards does not emphasizes their stability, but the shifting of their boundaries and their fluidity. In the hands of maintenance workers, signboards constitute unsteady multi-faceted objects (Denis and Pontille 2010b), they are agents of a potential mess. And workers deal with such an heterogeneity every day: each intervention inevitably goes with uncertainty about materials. Instead of being stable resources, the material properties of signboards are important issues of the maintenance work itself.

Second, heterogeneity must not be seen as a weakness. This would be the case if we thought about signboards as 'black-boxes' whose success would depend on their ability to remain closed and consistent. Conversely, the success of the wayfinding system rests on the capacity for signboards to be opened and closed by the people in charge of their maintenance, and on the ability of the latter not to focus on the primary boundaries of artifacts. In other words, the more the material properties resist to be splitted into bits and pieces and to be extended to others, the less is the system operative. This is precisely what is at stake when maintenance operators talk about signboards 'maintenability' (or lack of it): a quality that describes their easiness to be unfolded, and their diverse components to be accessed, disassembled and then reassembled.

\section{Fragility}

If signboards can not be seen as mere black-boxes, they are not eternal either. As time goes by, they get worn, as every other mundane object. Their colors fade out, the plastic sheets sometimes come unstuck (fig. 2). Moreover, as some subway lines go under the river (the 'Seine'), dampness is a strong issue in certain stations. There are leaks in some ceilings, and walls may get wet. As a consequence, plaster may crumble and boards may fall down or get themselves rusty (fig 3.).

Therefore, steadiness staged in the guidelines does not mean that, once put up on walls and ceilings, signboards remain inert. Shadowing maintenance workers all day long within the Parisian subway system, we actually face one mutation after another. In their eyes and in their hands, signboards are thus mutable objects. 


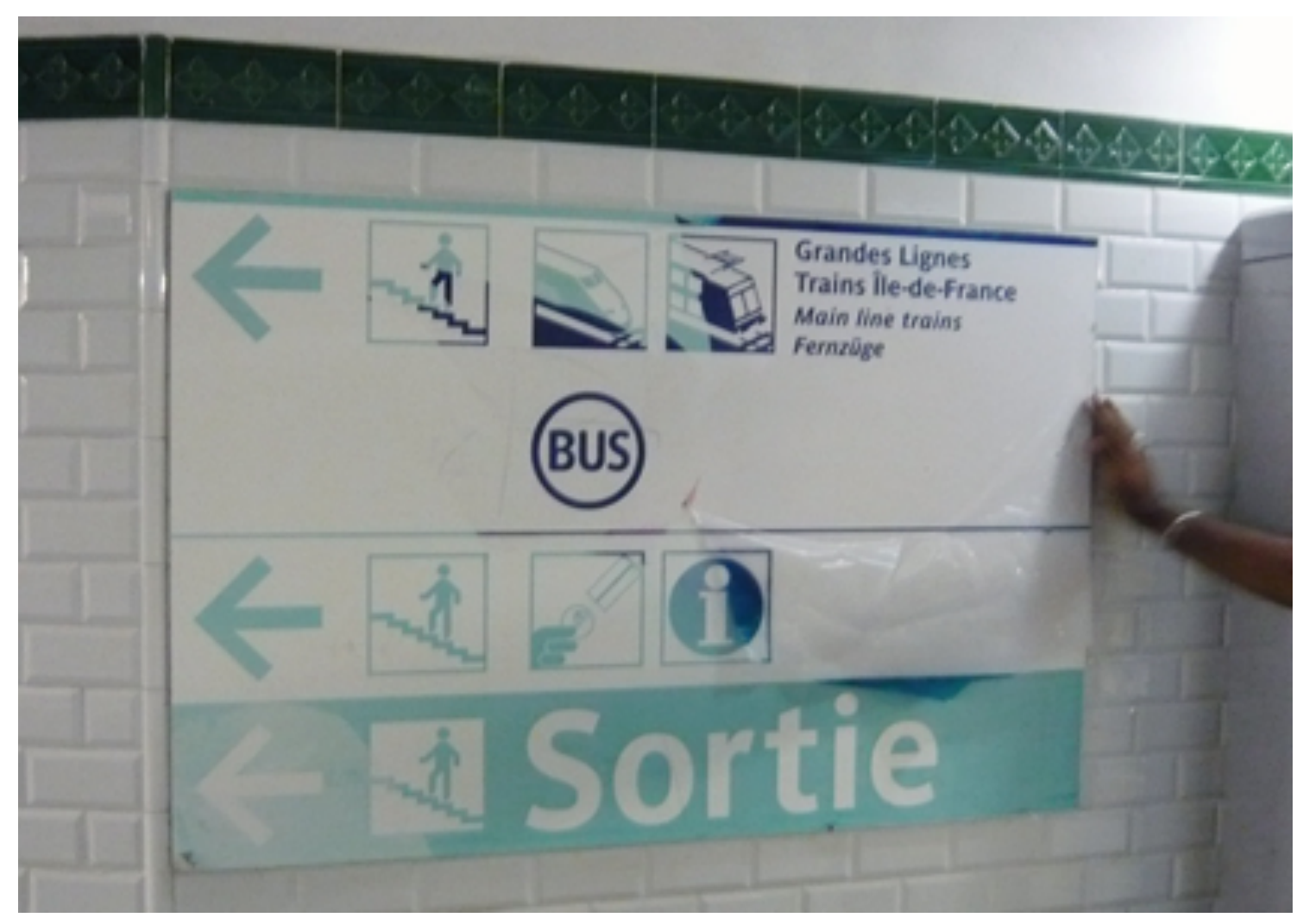

Figure 2. A discolored signboard

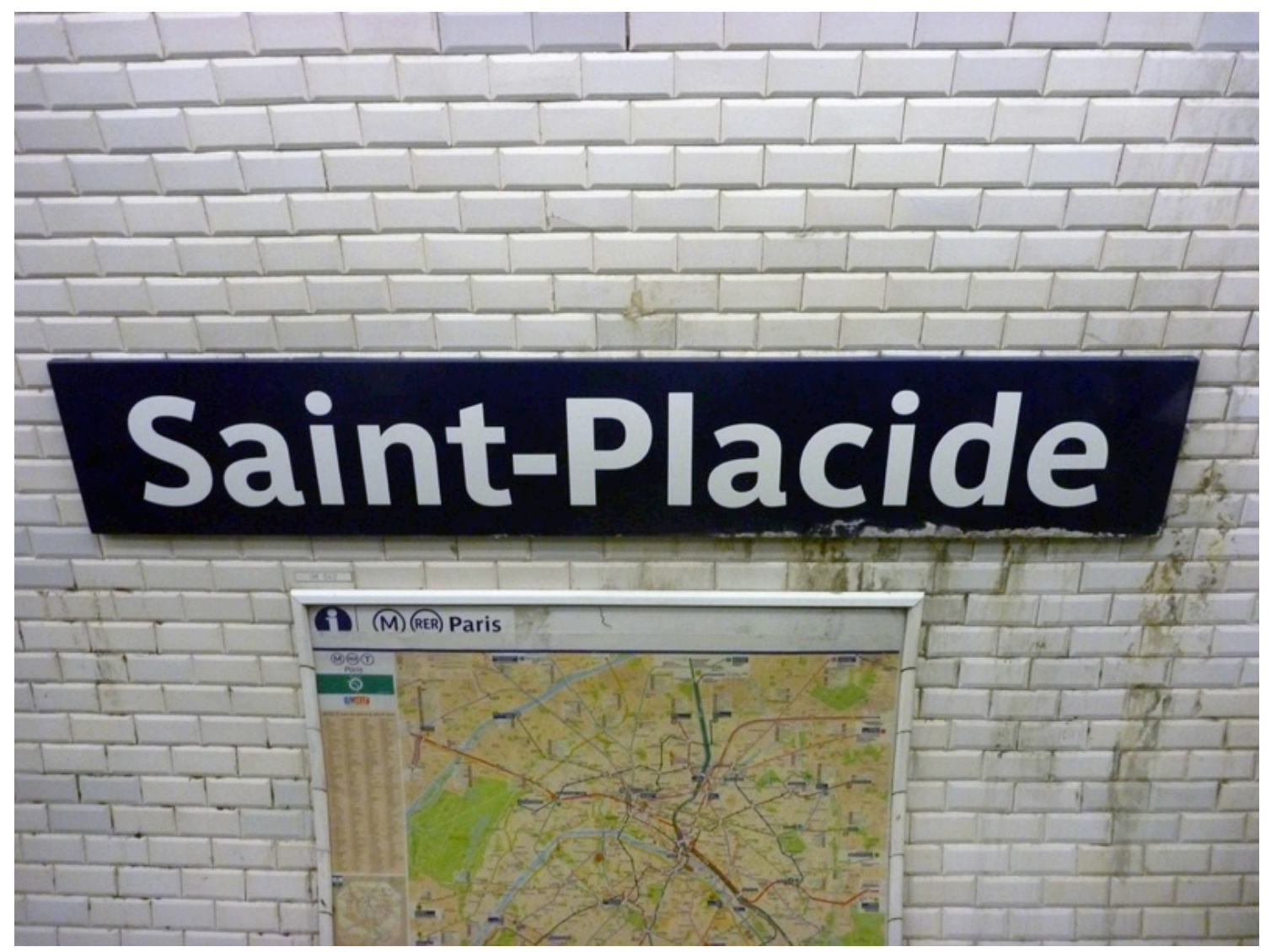

Figure 3. Mold on a signboard 
Wear and tear is not the only driving force of such a mutability. Signboards are also exposed to subway users and their various practices. While the majority of riders 'use' signboards only glancing at them, some are more active and become violent against them. For instance, some people intentionally hit or spoil them to express their dissatisfaction to the transportation carrier (or just to have fun). Some others are a lot more peaceful, but not less problematic, cherishing signboards so much that they steal them, as collectors or simply to decorate their own apartment. And among these unofficial practices, graffiti writers take of course also an important place. Not only they do graffiti on trains and on walls, but they regularly overlap signboards with tags or stickers.

Therefore, the mutability of signboards also comes from the various forms of violence they are exposed to. As public settings, subway spaces are more or less hostile environment within which the consistency of wayfinding system components, and even their very presence, are endangered.

Considering both wear and the various attacks they are subjected to, what strokes the observer of the maintenance work is the vulnerability of subway signs. Disassembling and reassembling practices never threaten signboards consistency: they are conducted by maintenance workers in the sake of the wayfinding system policy, in order to insure its dayto-day enforcement. Conversely, rust or blows go against it. They constitute unavoidable risks in the mundane life of publicly exposed artifacts.

What can we learn from this other foray in maintenance and its mess? First, we saw that it strongly contrasts with the version of standardized signboards as it appear in guidelines. When repaired and maintained, signboards are a lot more changing and unsteady than in the pages that detail their normalized measurements. But, more generally, it invites to seriously broaden our definition of matter by opening it to the various entities that maintenance workers take more or less directly into account. This is precisely what T. Ingold proposes when he insists, against material culture studies, to leave the very notion of materiality behind, in order to fully explore the diversity of materials, their relationships and their mutations.

It seemed to me that the concept of materiality, whatever it might mean, has become a real obstacle to sensible enquiry into materials, their transformations and affordances. (Ingold 2007: 12)

To endorse such a program, we have to examine the lushness of the material ecology in which signboards and their diverse components take part. Moreover, we have to acknowledge - against a simplistic focus on immutability - the vitality of things (Ingold 2007), their liveliness (Barad 2003). Enamel, ink, paint, plaster compose living organisms in constantly interacting with each others and with others. And during these interactions, these organisms mute in more or less dramatic ways.

What our inquiry into maintenance highlights is the very frangibility that goes with this vitality. Searching for the messy side of an ordering apparatus, we have eventually encountered its fragility. But does this result invalidates our first assertion about the Parisian subway wayfinding system? Does it mean that subway signs have nothing to do with any ordering processes? That their normalized immutability is just an illusion? Not necessarily. We can instead accept to break with a definition of order as a 'once and for all' stabilized state. This is what Henke (2000), and Graham and Thrift (2007) do when they insist on the importance of repair and maintenance. Drawing on Goffman's and Garfinkel's conception of mundane social order, these scholars show that material order is also subject to numerous reparations. It should be seen as the ongoing result of a permanent upkeep work: not a prior order, but a continuous ordering process. 
Such considerations about maintenance work do not deny the existence of ordering devices at all, neither do they leave all interest for matter behind. On the contrary, they prompt to seriously investigate the way such a work is accomplished and to analyze its place within organizations.

\section{Care}

Mol (2008) has recently identified specific practices in healthcare services, which she describes as the main features of a 'logic of care'. We think maintenance work has a lot to do with such a logic, and we suggest to follow her invitation - which appears in the epigram with which we started this paper - to transport, and translate, her analysis from healthcare services to other sites and situations. Indeed, we assume such a movement can help to more precisely understand what maintenance is. Our goal is also to get rid of the vocabulary of materiality-as-stability and to set the basis for a research program that would explore the possibilities of a 'care of thing'.

Mol articulates the 'logic of care' in contrast to what she terms the 'logic of choice', which emphasizes the capacity for patients to make decisions, 'individual choices' that empower them against medical expertise and its somehow inhumanity. The first, and essential, dimension of the 'logic of care' lies in the way it treats disease and fragility. Contrarily to the logic of choice, which is entirely focused on the autonomy of patients and the return to normality, 'the logic of care starts out form the fleshiness and the fragility of life' (Mol 2008: 11). Care practices accept the vulnerability of patients, they exist through it. We saw that such an assumption lies also at the core of maintenance practices. The latter are dedicated to material fragility, which is not considered as a temporary result of an extraordinary event (an accident or a breakdown) but as the mundane mode of existence of things. Maintenance, as care, 'takes failures to be an unavoidable part of life' (Mol 2008: 92). Studying maintenance as an occurrence of care thus allows to abandon a normative definition of material life implicitly based on presupposed health and order. For maintenance and care, there is no such thing as a 'normal situation'.

There is another element about care pointed by Mol about the work of repair technicians, that can bring a useful light on the maintenance work. Care is grounded on watchfulness and attention: it can not be normalized. As what is wrong can not be completely settled in advance, it demands constant adaptation. This is why maintenance gives so much contrast with designers guidelines. Improvisation is the main fuel of maintenance operators (Henke 2000) whose interventions always overwhelm the normalized procedures (Orr 1996).

Finally, the confrontation of maintenance with the logic of care invites to explore another aspect, which highlights important differences. Describing the logic of care, Mol insists on the distribution of practices through large collectives. Contrarily to the logic of choice, which stages and isolates individual patients and medical experts, care are shared between professionals (practicians, nurses...) and lay persons (patients, family, friends...) who act hand in hand.

This is not exactly how maintenance works. Within the Parisian subway system, only the operators we followed are committed to the maintenance of signboards. This has a lot to do with their ability to notice tiny mutations before anybody else. This is basically their job: taking care of things before everyone even notices any change and so, avoiding breakdowns and incidents. Indeed, maintenance workers share what Goodwin (1994) terms a 'professional vision': not a stock of knowledge or a gift, but collective and situated accomplishments made of gazes, discursive practices, and material representations. As Orr (1996) showed it, such a professional know how is built not only in front of the objects that have to be repaired, but also during pauses, lunches, where stories and advices continuously 
circulate. These (mostly secret) stories and the vision they nourish, are the lively roots of occupational communities such as repair technicians and maintenance operators.

In the case of subway signs, there is however a dimension that brings back maintenance close to the care practices that Mol depicted. The professional vision thanks to which they can be aware of signboards mutabilities is by no means considered by operators as their exclusive domain. On the contrary, they regularly try to make others sensitive to it. One of their leitmotiv is to get people aware of the necessity of taking care of signboards. This is particularly the case of stations superintendants who are supposed to report anomalies when opening the station. During our observations, we witnessed several harsh discussions between maintenance operators and superintendants about reports that have not be done correctly (or not at all), the former explaining in details the way the latter should do to look at boards and to notice their transformation, if not their absence.

There is thus some distribution. Maintenance is not entirely taken in charge by an occupational community (Orr 1996). Yet, this distribution has its limits. Riders themselves are not at all involved in signboards maintenance. As they are the ones towards who subway signs are addressed, a strong boarder seems to be drawn between 'them' and the different workers. We think such a separation is not a specificity of the care of things. Indeed we know situations where users are explicitly enrolled in maintenance practices. For instance, this is crucial in information security management (Denis and Pontille 2011). However it raises an important issue about care, and especially material one: its relationship with visibility and invisibility. In the case of $\mathrm{Mol}$, care practices are visible to (and accomplished by) almost everyone. Conversely, the care of such normalized and standardized things as subway signs seems to go with the performation of two regions: the users one and its backrooms. Maintenance here enacts a two-sided object, both consistent and vulnerable, both immutable and mutable.

\section{Conclusion}

Examining the way maintenance workers treat signs is a useful means to avoid the flattening effect of the materiality-as-stability approach. The stability and immutability of organizational artifacts, even 'ordering' ones, are not ontological properties: they are the result of an exploratory and improvised maintenance work that consists in constantly taking care of things and being aware of their material multiplicity. What matters for maintenance workers, what their action is mainly oriented toward to, is by no means the 'materiality' of things. Rather, in their daily practices they deal with both the very heterogeneity of materials and the fragility of organisms.

In many respects, this logic of care enacts a singular version of matter. By following the people in charge of the maintenance of Parisian wayfinding system, we saw how important this logic is. But we also highlighted its relative nature. The logic of care is supported by certain actors only, and it clearly contrasts with another one within the organization: the logic of normalization and standardization. So, even though everyone in the carrier (and probably in the subway spaces themselves) assumes they are dealing with the same signboards, the logic of ordering and the logic of care can be seen as two specific 'modes of mattering' (Law 2010), two distinct forms of enacting matter. While, in the first one, material properties of signboards are meant to constitute reliable resources for riders, they compose, in the second one, assemblages whose consistency and solidity remain always uncertain. In other words, as ordering devices, the material agentivity of signboards is a matter of fact, while as object of maintenance work it is a matter of care (Puig de la Bellacasa 2010).

Post-ANT studies generally analyze such diversity of versions of reality as the result of the coexistence of distinct networks that involve different places, rhythms, persons, artifacts and 
devices (Gad and Jensen 2010). Depending on the nature of the networks, the relationships of the versions vary: multiple versions may be completely separated from one another, two versions may contradict each other, or one version may include others (Law 2010). In our case, the different material versions of signboards do not only coexist: they are strongly relational. Not only they occur in the same place (the subway spaces), but one version directly depends on the other. The possibility for riders to rely on subway signs as immutable artifacts that perform a stabilized environment is tied to the workers' ability to handle the same subway signs as mutable objects that have to be constantly repaired and replaced. In other terms, one version is dedicated to the other. The material ordering of the world goes through the care of things.

\section{References}

Barad, K. 2003. Posthumanist Performativity: Toward an Understanding of How Matter Comes to Matter. Signs: Journal of Women in Culture and Society, 28(3), pp. 801-831.

Cooren, F., 2010. Action and Agency in Dialogue: Passion, Incarnation and Ventriloquism, Amsterdam / Philadelphia, John Benjamins.

Denis, J., and Pontille, D., 2010a. Petite sociologie de la signalétique. Les coulisses des panneaux du métro, Paris: Les Presses Mines ParisTech.

Denis, J., and Pontille, D., 2010b. Placing Subway Signs: Practical Properties of Signs at Work. Visual Communication, 9(7), pp. 441-462.

Denis, J., and Pontille, D., 2011. Organization, Materiality, Maintenance. Paper presented at the 61st Annual Conference of the International Communication Association, Panel 'The Communicative and Material Constitution of Organization. Studying Objects, Texts and Sites', Boston, MA, 26-30 May.

Fuller, G., 2002. The Arrow-Directional Semiotics: Wayfinding in Transit. Social Semiotics, 12 (3), pp. 231-178.

Gad, C., and Jensen, C.B., 2010. On the Consequences of Post-ANT. Science, Technology \& Human Values, 35(1), pp. 55-80.

Garfinkel, H,. 1996. Ethnomethodology's program. Social Psychology Quarterly, 59(1), pp. 5-21.

Gherardi, S., 2001. From Organizational Learning to Practice-Based Knowing. Human Relations, 54(1), pp.131-139.

Goodwin, C. 1994. Professional Vision. American Anthropologist, 96(3), pp. 606-633.

Graham, S., and Thrift, N., 2007. Out of Order: Understanding Repair and Maintenance. Theory, Culture \& Society, 24(3), pp.1-25.

Henke, C.R., 2000. The Mechanics of Workplace Order: Toward a Sociology of Repair. Berkeley Journal of Sociology, 44, pp. 55-81.

Ingold, T., 2007. Materials against materiality. Archaeological Dialogues, 14(1), pp. 1-16.

Knox, H., O'Doherty, D., Vurdudakis, T. and Westrup, C., 2008. Enacting Airports: Space, Movement and Modes of Ordering, Organization, 15(6), pp. 869-888.

Latour, B., 2007. Reassembling the Social: An Introduction to Actor-Network-Theory, Oxford University Press, USA.

Law, J., 1999. After ANT: complexity, naming and topology. In John Law and J. Hassard, (eds), Actor Network Theory and After. Oxford: Wiley-Blackwell, pp. 1-14.

Law, J., 2004. After Method: Mess in Social Science Research, London, Routledge. 
Law, J., 2010. The Materials of STS. In Dan Hicks and Mary Beaudry (eds), The Oxford Handbook of Material Culture Studies, Oxford, Oxford University Press, pp. 171-186.

Law, J., and Singleton V., 2000. Performing Technology's Stories: On Social Constructivism, Performance, and Performativity. Technology and Culture, 41, pp. 765-775.

Leonardi, P.M. 2010. Digital materiality? How artifacts without matter, matter. First Monday, 15(6-7). (http://firstmonday.org/htbin/cgiwrap/bin/ojs/index. php/fm/article/viewArticle/ 3036/2567).

Leonardi, P., and Barley, S., 2008. Materiality and Change: Challenges to Building Better Theory about Technology and Organizing. Information and Organization, 18(3), pp.159-176.

Mol, A., and Law, J., 1994. Regions, Networks and Fluids: Anaemia and Social Topology. Social Studies of Science, 24(4), pp. 641-671.

Mol, A., 1999. Ontological politics. A word and some questions. In John Law and J. Hassard, (eds), Actor Network Theory and After. Oxford, pp. 74-89.

Mol, A., 2008. The Logic of Care, New York: Routledge.

Orlikowski, W.J., 2000. Using Technology and Constituting Structures: A Practice Lens for Studying Technology in Organizations. Organization Science, 11(4), pp. 404-428.

Orlikowski, W.J., 2007. Sociomaterial Practices: Exploring Technology at Work. Organization Studies, 28(9), pp. 1435-1448.

Orlikowski, W.J., and Barley, S.R. 2001. Technology and institutions: What information systems research and organization studies can learn from each other. MIS Quarterly, 25, pp. 145-165.

Orr, J.E., 1996. Talking About Machines: An Ethnography of a Modern Job, Cornell University Press.

Pels, D., Hetherington, K. and Vandenberghe, F., 2002. The Status of the Object. Performances, Mediations, and Techniques. Theory, Culture \& Society, 19(5/6), pp. 1-21.

Pickering, A., 1995. The Mangle of Practice: Time, Agency, and Science, Chicago: The University of Chicago Press.

Puig de la Bellacasa, M., 2010. Matters of Care in Technoscience: Assembling Neglected Things. Social Studies of Science, 41(1), pp. 85-106.

RATP. 1997. Signalétique multimodale. La RATP fait signe aux voyageurs. Internal document, Département des projets, Conception de l'information, $12 \mathrm{p}$.

RATP. 2007. Guide Information Voyageurs, Dénomination des gares, stations et arrêts. Internal document, Unité Conception et Identité des Espaces, $25 \mathrm{p}$.

Star, S.L. (ed), 1995. Ecologies of Knowledge: Work and Politics in Science and Technology, State University of New York Press.

Suchman, L.A., 1987. Plans and Situated Actions: The Problem of Human-Machine Communication, Cambridge University Press. 